\title{
Myeloperoxidase level and inflammatory markers and lipid and lipoprotein parameters in stable coronary artery disease
}

\author{
Elżbieta Kimak ${ }^{1 *}$, Bartosz Zięba ${ }^{1,2}$, Dariusz Duma ${ }^{1}$ and Janusz Solski ${ }^{1}$
}

\begin{abstract}
Background: Myeloperoxidase (MPO) impairing endothelial functions. We investigated whether increasing concentration of myeloperoxidase (MPO) and inflammatory markers induce progression and incident acute coronary syndrome (ACS) in stable coronary artery disease (SCAD) patients. Therefore, the concentration of MPO, lipids, lipoproteins (apo(apolipoprotein) Al, apoB, lipoprotein associated phospholipase A2 (LpPLA2) level), inflammatory markers (high sensitivity C-reactive protein (hsCRP), tumor necrosis factor-a (TNF-a), interleukine-6 (IL-6) concentration) were examined.

Methods: This study concerned 67 SCAD patients divided into groups: all patients, patients with MPO $<200 \mathrm{ng} / \mathrm{ml}$, MPO 200-300 ng/ml, MPO > $300 \mathrm{ng} / \mathrm{ml}$ concentration and 15 controls. ApoAl, apoB and hsCRP levels were examined using the immunonephelometric method, and MPO, LPPLA2, IL-6, TNF-a concentration was performed by using Quantikine ELISA kit R\&D Systems.

Results: In the all patients, and in group with MPO 200-300 ng/ml TC, LDL-C, nonHDL-C, LpPLA2 concentration and TC/ HDL-C, LDL-C/HDL-C ratios were insignificant, and significantly higher concentration of TG, apoB, MPO, inflammatory markers and TG/HDL-C, MPO/apoAl, MPO/HDL-C ratios but HDL-C, apoAl level and HDL-C/apoAl ratio were significantly reduced. In the group of patients with $M P O<200 \mathrm{ng} / \mathrm{ml}$, level of TC, LDL-C, nonHDL-C, apoAl, apoAll, LPPLA2 and MPO and LDL-C/HDL-C ratio were in-significant, $\mathrm{HDL}-\mathrm{C}$ was decreased but apoB, TG, inflammatory markers, apoB/apoAl, TG/ $\mathrm{HDL}-\mathrm{C}, \mathrm{MPO} / \mathrm{apoAl}, \mathrm{MPO} / \mathrm{HDL}-\mathrm{C}$ ratio were significantly increased. In the group of patients with $\mathrm{MPO}>300 \mathrm{ng} / \mathrm{ml}$ concentration of TC, LDL-C, nonHDL-C, apoAll, LPPLA2 and LDL-C/HDL-C ratios were not significant, but HDL-C and apoAl concentrations were significantly decreased. The concentrations of $\mathrm{TG}$, apoB, MPO and inflammatory markers and TG/HDL-C, MPO/apoAl, MPO/HDL-C ratios were significantly increased compared to the controls. The apoAl concentration was significantly decreased and the concentration of MPO and hsCRP as well as MPO/apoAl and MPO/ $\mathrm{HDL}-\mathrm{C}$ ratios were significantly higher as compared to the group of patients with $\mathrm{MPO}<200 \mathrm{ng} / \mathrm{ml}$. Spearman's correlation test showed a positive correlation between MPO concentration and MPO/apoAl and MPO/HDLC ratios in all patients and MPO $<200 \mathrm{ng} / \mathrm{ml}, \mathrm{MPO} 200-300 \mathrm{ng} / \mathrm{ml}$. The patients with MPO $>300 \mathrm{ng} / \mathrm{ml}$ showed a positive correlation between the concentration of MPO and the level of hsCRP and IL-6, and a negative correlation between MPO/apoAl ratio and the concentration of HDL-C, apoAl and apoAll.

(Continued on next page)
\end{abstract}

\footnotetext{
*Correspondence: elzbieta.kimak@wp.pl; elzbieta.kimak@umlub.pl

${ }^{1}$ Department of Laboratory Diagnostics, Medical University, Street Chodźki 1,

20-093 Lublin, Poland

Full list of author information is available at the end of the article
}

(c) The Author(s). 2018 Open Access This article is distributed under the terms of the Creative Commons Attribution 4.0 International License (http://creativecommons.org/licenses/by/4.0/), which permits unrestricted use, distribution, and reproduction in any medium, provided you give appropriate credit to the original author(s) and the source, provide a link to the Creative Commons license, and indicate if changes were made. The Creative Commons Public Domain Dedication waiver (http://creativecommons.org/publicdomain/zero/1.0/) applies to the data made available in this article, unless otherwise stated. 
(Continued from previous page)

Conclusion: The results suggest that moderate dyslipidemia and dyslipoproteinemia deepening of inflammation, and inflammation slowly induce increase MPO concentration which decrease apoAl and HDL-C level and disturb HDLs function. The increasing MPO level and MPO/HDL-C, MPO/apoAl ratios can differentiate the SCAD patients at the risk of acute coronary syndrome (ACAD) and stroke.

Keywords: Myeloperoxidase, Inflammatory markers, Lipids, Lipoproteins, Stable coronary

\section{Background}

Patients with stable coronary artery disease (SCAD) are a heterogenous group in terms of the progression rate of the disease, the severity of coronary lesions and the occurrence of acute coronary syndromes (ACS) [1-3]. Oxidative stress and inflammation play the direct role in the initial and progression of atherosclerosis plaques and development of cardiovascular artery disease $(\mathrm{CAD})[4,5]$. A high density lipoprotein (HDL) protects against coronary artery disease (CAD) mainly by reverse cholesterol transport. Moreover, HDL has anti-inflammatory, antioxidative, in part via paraoxonase-1 (PON-1), antithrombotic and anti-apoptotic properties, increased endothelial cells (EC), nitric oxide synthase, enhanced endothelial progenitor cells (EPC) mediating vasculoprotection, stimulation of endothelial cell proliferation and migration [6]. Myeloperoxidase (MPO), a product of systemic inflammation plays important role both in the process of oxidative stress and inflammation and promotes oxidation of lipoproteins [5]. MPO is a leukocytederived enzyme that catalyzes the formation of oxidative reactants and participates in innate immunity against infections. MPO is a potential participant in promotion and propagation of atherosclerosis [7] and impairing endothelial function, it can participate in destabilization of atherosclerotic plaques [8]. Myeloperoxidase selectively induces HDL oxidation within the artery wall converting anti-atherogenic lipoprotein into potential atherogenic forms $[7,8]$. Myeloperoxidase (MPO) concentrations predict adverse clinical outcomes in setting acute coronary syndromes (ACS) and heart failure, but the prognostic role of MPO in SCAD with atherosclerotic burden is poorly understood [9]. Unfortunately, there is little information indicating the influence the $\mathrm{MPO}$ and inflammatory markers level on the concentration of apoAI and HDL-C and the stability of atherosclerotic plaques in SCAD patients.

The aim of the study was to investigate whether increasing concentration of myeloperoxidase (MPO) and inflammatory markers induce progression and incident ACS in groups of patients with stable cardiovascular artery disease patients. Therefore, the authors decided to examine the concentration of MPO, lipids, lipoproteins (apo(apolipoprotein)AI, apoB, lipoprotein associated phospholipase A2 (LPPLA2) level), inflammatory markers (high sensitivity C-reactive protein (hsCRP), tumor necrosis factor- $\alpha$ (TNF- $\alpha$ ), interleukine-6 (IL-6) concentration) in SCAD patients.

\section{Methods}

\section{Patients}

This study concerned 67 patients with SCAD, 38 females and 29 males, aged 56-70 years, hospitalized in the Department of Cardiology of the Provincial Specialistics Cardinal Stefan Wyszynski Hospital in Lublin, Poland. All patients in this study received acetyl salicylic acid and statin and were treated according to the ESC Guidelines on the treatment of stable coronary artery disease [10]. Patients with acute and chronic renal failure, liver disease, active autoimmune disease, cancer, thyroid disease, alcoholism and smokers and former smokers were excluded from the study. In the group of patients with hypertension were those receiving antihypertensive drugs which did not affect the status of lipid and lipoprotein. Diabetes mellitus was defined in patients under active treatment with insulin or oral hypoglycemic medication. All patients were divided into groups: concentration of $\mathrm{MPO}<200 \mathrm{ng} / \mathrm{ml}, \mathrm{MPO} 200-300 \mathrm{ng} / \mathrm{ml}$ and $\mathrm{MPO}>300 \mathrm{ng} / \mathrm{ml}$. The control group consisted of 15 healthy volunteers with no risk factors for cardiovascular disease, non-smoking, non-taking any medication, and without ischemic heart disease, 10 females and 5 males, aged 27-55 years. The study excluded pregnant women and using hormonal contraception. The qualification basis of volunteers to the control group was normal medical history and laboratory parameters.

\section{Sample preparation}

The material for the study was blood serum of patients with SCAD and healthy people. The patients' blood serum was collected after $14 \mathrm{~h}$ of fasting. For blood serum collection the system of vacuum tubes of sarstedt company was used without anticoagulant. In the fresh serum routine laboratory and lipid parameters were determined. The remainder of the sera was aliquoted, frozen and stored at $-80^{\circ} \mathrm{C}$.

\section{Determination of lipids, lipoproteins, hsCRP}

Lipids (total cholesterol (TC), LDL-cholesterol (LDL-C), HDL-cholesterol (HDL-C) was determined by routine 
methods on the Siemens analyzer (Germany), whereas lipoprotein apoAI, apoB, hsCRP by using the immunonephelometric method on BNII Nephelometer BNII (Germany) (Siemens GmbH, Germany). Non-HDL cholesterol (nonHDL-C) was calculated as TC minus HDL-C.

\section{Determination of MPO, IL- 6 , TNF- $\alpha$ and LpPLAG7}

Determination of IL-6, TNF- $\alpha$, LPPLA2G7, MPO was performed by using Quantikine ELISA kit R\&D Systems, Inc., USA \& Canada. The concentration of human IL-6 or TNF- $\alpha$ or LPPLA2G7 or MPO in serum was measured by the sandwich enzyme immunoassay kit. The microplates were pre-coated with monoclonal antibody specific for IL-6 or TNF- $\alpha$ or LpPLA2G7 or MPO. The samples and standards were pipetted into wells in which they were bound by an immobilized antibody. After incubation every microplate was washed with a washing reagent. Then enzyme-linked polyclonal antibody specific for IL-6, or TNF- $\alpha$ or LpPLA2G7 or MPO was added to the wells. After that another incubation amplifier solution was added to the wells. The measured intensity of the developing color was proportional to the concentration of IL-6, or TNF- $\alpha$ or LPPLA2G7 or MPO.

\section{Statistical analyses}

The statistical analyses were performed using STATISTICA software (StatSoft, Krakow, Poland). The normal distribution of the analysed parameters was assessed by the Shapiro-Wilk test. For comparison, of more than two groups the Kruskal-Wallis test was used. The relation between the variables was examined by Spearman's correlation analysis. The data were expressed as medians (minimum-maximum). The statistical significance of all variables was established at $p<0.05$.

\section{Results}

The clinical parameters in SCAD patients and controls are shown in Table 1. In all patients diabetes mellitus occurred in 12 patients (18\%), and obesity and overweight in 49 patients (73\%). Concentration of myeloperoxidase, inflammatory markers and lipid and lipoprotein and lipid and lipoprotein ratios in the patients and the reference group are presented in Table 2. The results showed dyslipidemia and dyslipoproteinemia in SCAD patients. The concentration of lipids and lipoproteins and inflammatory markers of patients were varied and indicated their disturbances. Therefore, groups of all patients, patients with $\mathrm{MPO}<200 \mathrm{ng} / \mathrm{ml}$, MPO 200 $300 \mathrm{ng} \mathrm{ml}$ and $\mathrm{MPO}>300 \mathrm{ng} / \mathrm{ml}$ level were separated. The division of patients into groups according to the increasing concentration of MPO caused the selection of patients with deteriorating inflammatory markers which accompanied deteriorating dyslipidemia and dyslipoproteinemia. In the all group of SCAD patients, TC, LDL-C, nonHDL-C, LpPLA2 concentration and TC/HDL-C, LDL-C/HDL-C ratios were statistically insignificant but HDL-C, apoAI level and HDL-C/apoAI ratio were significantly reduced as compared to the controls. In contrast, the concentrations of TG, apoB, inflammatory markers (MPO, hsCRP, TNF- $\alpha$, IL-6,) and TG/HDL-C, apoB/apoAI, MPO/apoAI and MPO/HDL-C ratios were significantly increased. In the group of patients with $\mathrm{MPO}<200 \mathrm{ng} / \mathrm{ml}$, level of TC, LDL-C, nonHDL-C, apoAI, apoAII, LpPLA2 and MPO and LDL-C/HDL-C ratio were in-significantly as compared to controls. However, the concentrations of TG, apoB, hsCRP, TNF$\alpha$ and IL- 6 and apoB/apoAI, MPO/apoAI and MPO/ HDL-C ratios were significantly higher than controls. In the group of patients with concentration of MPO 200$300 \mathrm{ng} \mathrm{ml}$, significantly decreased HDL-C and apoAI level and HDL-C/apoAI ratio, and significantly higher concentration of TG, apoB, inflammatory markers (MPO, hsCRP, TNF- $\alpha$, IL-6 level) and TG/HDL-C, apoB/apoAI, MPO/apoAI, MPO/HDL-C ratios were observed. However, level of TC, LDL-C, nonHDL-C, apoAII, LpPLA2 and TC/HDL-C, LDL-C/HDL-C ratios were in-significant as compared to controls.

In the group of patients with $\mathrm{MPO}>300 \mathrm{ng} / \mathrm{ml}$ concentration of TC, LDL-C, nonHDL-C, apoAII, LpPLA2 and LDL-C/HDL-C ratios were not statistically significant, but HDL-C and apoAI concentration and HDL-C/ apoAI were significantly decreased. The concentrations of TG, apoB, MPO and inflammatory markers (MPO, hsCRP, TNF- $\alpha$, IL-6 level) and TG/HDL-C, apoB/apoAI,

Table 1 Clinical parameters and the reference group in SCAD patients (median (min-max)

\begin{tabular}{|c|c|c|c|c|c|}
\hline & $\mathrm{MPO}<200 \mathrm{ng} / \mathrm{ml}, n=26$ & $\mathrm{MPO}=200-300 \mathrm{ng} / \mathrm{ml} n=26$ & $\mathrm{MPO}>300 \mathrm{ng} / \mathrm{ml} n=15$ & MPO ng/ml $n=67$ & Controls $n=15$ \\
\hline Ages (years) & $61(58-67$ & $66(56-70)$ & $63(58-68)$ & $63(56-70)$ & $55(27-55)$ \\
\hline Gender (male/ female) & $14 \mathrm{~F}, 12 \mathrm{M}$ & $15 \mathrm{~F}, 11 \mathrm{M}$ & $9 \mathrm{~F}, 6 \mathrm{M}$ & $38 \mathrm{~F}, 29 \mathrm{M}$ & $10 \mathrm{~F}, 5 \mathrm{M}$ \\
\hline BMI $\left(\mathrm{kg} / \mathrm{m}^{2}\right)$ & $28.4(25-30)$ & $27.6(24.5-29.4)$ & $28.1(25.1-34.9)$ & $28.0(24.5-34.9)$ & $25(22-27)$ \\
\hline eGFR (ml/min/1.73 m2) & $95.1(84.4-103.6)$ & $83(63-94.6)$ & $79(69-109)$ & $90(63-109)$ & $125(95-160)$ \\
\hline Creatinine $(\mu \mathrm{mol} / \mathrm{L})$ & $87(77-94)$ & $80(64-92)$ & $87(65-97)$ & $80(72-97)$ & $97(71-108)$ \\
\hline Hypertension & $n=9$ & $n=10$ & $n=12$ & 31 & - \\
\hline Diabetes mellitus & - & 4 & 8 & 12 & - \\
\hline
\end{tabular}


Table 2 Myeloperoxidase level, inflammatory markers, lipid, lipoprotein parameters and lipid and lipoprotein ratios in SCAD patients and the reference group (median (minimum-maximum)

\begin{tabular}{|c|c|c|c|c|c|}
\hline & $\mathrm{MPO}<200 \mathrm{ng} / \mathrm{ml}, n=26$ & MPO200-300 ng/ml $n=26$ & $\mathrm{MPO}>300 \mathrm{ng} / \mathrm{ml} n=15$ & MPO ng/ml n=67 & Controls $n=15$ \\
\hline $\mathrm{TC}(\mathrm{mmol} / \mathrm{L})$ & $4.50(3.73-5.02)$ & $3.91(3.41-4.64)$ & $3.99(3.03-7.74)$ & $4.33(3.03-7.74)$ & $4.87(2.79-5.18)$ \\
\hline LDL-C (mmol/L) & $2.48(1.96-3.09)$ & $2.30(3.95-3.10)$ & $2.20(1.32-5.49)$ & $2.38(1.96-5.49)$ & $3.03(1.10-3.99)$ \\
\hline $\mathrm{HDL}-\mathrm{C}(\mathrm{mmol} / \mathrm{L})$ & $1.08(0.93-1.32)^{* *}$ & $1.08(1.01-1.42)^{* *}$ & $0.95(0.60-1.42)^{* * *}$ & $1.07(0.60-1.42)^{* *}$ & $1.55(1.14-2.30)$ \\
\hline TG (mmol/L) & $1.88(1.58-2.73)^{*}$ & $1.67(0.93-2.12)^{*}$ & $1.72(0.93-3.91)^{*}$ & $1.75(0.93-3.91)^{*}$ & $1.06(0.34-2.70)$ \\
\hline nonHDL-C (mmol/L) & $1.51(1.16-1.71)$ & $1.19(0.93-1.45)$ & $1.32(1.07-1.70)$ & $1.40(0.93-1.71)$ & $1.06(0.34-2.70)$ \\
\hline apoAl (g/L) & $1.45(1.20-1.51)$ & $1.39(1.29-1.60)^{*}$ & $1.29(1.15-1.75)^{* * \uparrow}$ & $1.38(1.15-1.75)^{*}$ & $1.57(1.35-1.99)$ \\
\hline apoAll(g/L) & $0.29(0.27-0.32)$ & $0.28(0.25-0.34)$ & $0.29(0.25-0.34)$ & $0.29(0.25-0.34)$ & $0.32(0.29-0.38)$ \\
\hline ApoB (g/L) & $0.93(0.864-1.26)^{*}$ & $0.90(0.67-1.12)^{*}$ & $0.96(0.63-1.16)^{*}$ & $0.94(0.63-1.25)^{*}$ & $0.70(0.41-1.17)$ \\
\hline LpPLA2 (ng/ml) & $101(86-185)$ & $98(67-164)$ & $112(79-126)$ & $103(67-185)$ & $72.4(32-172.1)$ \\
\hline $\mathrm{TC} / \mathrm{HDL}-\mathrm{C}$ & $4.15(3.39-5.36)^{*}$ & $3.59(1.58-5.80)$ & $4.10(3.39-4.77)^{*}$ & $3.79(1.58-5.80)$ & $3.13(2.60-3.71)$ \\
\hline LDL-C/HDL-C & $2.26(2.09-3.13)$ & $2.14(1.25-2.59)$ & $2.28(1.76-2.81)$ & $2.25(1.25-2.81)$ & $1.95(1.31-2.40)$ \\
\hline TG/HDL-C & $3.90(2.04-6.19)^{*}$ & $3.52(1.79-3.9)^{*}$ & $3.90(1.65-4.76)^{*}$ & $3.48(1.79-6.19)^{*}$ & $1.60(1.12-3.02)$ \\
\hline apoB/apoAl & $0.62(0.60-0.90)^{*}$ & $0.65(0.46-0.84)^{*}$ & $0.75(0.55-0.86)^{* *}$ & $0.69(0.55-0.90)^{* *}$ & $0.46(0.27-0.64)$ \\
\hline HDL-C/apoAl & $0.30(0.27-0.36)^{* *}$ & $0.31(0.29-0.38)^{* *}$ & $0.29(0.26-0.37)^{* *} \uparrow$ & $0.31(0.26-0.38)^{* *}$ & $0.39(0.32-0.46)$ \\
\hline MPO ng/ml & $138(72.4-176)$ & $230(203-263)^{* *}$ & $350(303-393)^{* * *}$ & $229(72.4-393)^{* *}$ & $90.0(49-153)$ \\
\hline hsCRP ( $\mu \mathrm{g} / \mathrm{ml})$ & $0.141(0.086-0.28)^{* *}$ & $0.157(0.086-0.38)^{* *}$ & $0.21(0.086-1.38)^{* * * \uparrow} \uparrow$ & $0.152(0.086-1.38)^{* *}$ & $0.09(0.02-0.5)$ \\
\hline TNF-alfa (pg/ml) & $5.23(4.8-8.3)^{* * *}$ & $5.31(4.18-6.25)^{* * *}$ & $5.80(4.86-6.61)^{* * *}$ & $5.35(4.18-8.3)^{* * *}$ & $1.20(0.60-1.21)$ \\
\hline IL-6 (pg/ml) & $1.74(0.84-3.51)^{* *}$ & $2.54(1.42-3.50)^{* * *}$ & $3.02(2.36-3.80)^{* * *}$ & $2.64(0.84-3.80)^{* * *}$ & $0.40(0.20-0.83)$ \\
\hline MPO/apoAl & $0.95(0.61-1.10)^{*}$ & $1.65(1.46-1.88)^{* *}$ & $2.72(2.05-2.92)^{* * * \uparrow} \uparrow$ & $1.67(0.61-2.92)^{* *}$ & $0.55(0.26-2.53)$ \\
\hline MPO/HDL-C & $2.51(1.84-4.14)^{*}$ & $5.41(3.95-5.94)^{* *}$ & $8.51(5.60-9.15)^{* * *} \uparrow$ & $5.23(1.84-5.94)^{* *}$ & $1.48(0.63-4.51)$ \\
\hline
\end{tabular}

MPO myeloperoxidase, SCAD stable cardiovascular artery disease

${ }^{*} P<0.05$; ${ }^{* *} P<0.01$; ${ }^{* * *} P<0.001$ vs. the reference group; $\uparrow P<0.05$ vs. the group of MPO $200 \mathrm{ng} / \mathrm{ml}$

$\mathrm{MPO} / \mathrm{apoAI}$ and MPO/HDL-C ratios were significantly increased compared to the control group. Moreover, the apoAI concentration was significantly decreased and the concentration of MPO and hsCRP as well as MPO/ apoAI and MPO/HDL-C ratios were significantly higher as compared to the group of patients with $\mathrm{MPO}<$ $200 \mathrm{ng} / \mathrm{ml}$.

Levels of TC, LDL-C and TC/HDL-C and LDL-C/ HDL-C ratios were decreased and were dependent on statin treatment. However, statins therapy reduced TG level at a small degree and did not increase HDL-C and apoAI levels. Moreover, concentration of triglyceride rich-lipoproteins (TRLs) and cholesterol-rich lipoproteins (apoB-containing lipoproteins) were increased as TG and apoB concentration and TG/HDL ratio showed.

Correlations were calculated for each group separately. In all patients a significant positive correlation were observed between concentration of MPO and apoAI $(R=0.917 ; p=0.000)$ and between MPO and MPO/ HDL-C $(R=0.838 ; p=0.000)$.

In patients with $\mathrm{MPO}<200 \mathrm{ng} / \mathrm{ml}$ a significant positive correlation occurred between the concentration of $\mathrm{MPO}$ and MPO/apoAI ratio $(R=0.853, p=0.00001)$ and a significant positive correlation between MPO level and MPO/HDL-C ratio $(R=0.729, p=0.00002)$. In patients with MPO 200-300 ng/ml level a significant positive correlation between MPO concentration and $\mathrm{MPO} /$ apoAI ratio $(R=0.548, p=0.003)$ and between MPO level and MPO/HDL-C ratio $(r=0.428, p=0.029)$ was observed. However, in patients with $\mathrm{MPO}>300 \mathrm{ng} / \mathrm{ml}$ level a significant positive correlation between MPO level and hsCRP concentration $(R=0.719, p=0.0044)$, between MPO level and IL-6 concentration $(R=0.857, p=0$. 0065), and a significant negative correlation between $\mathrm{MPO} /$ apoAI ratio and apoAI level $(R=-0.758, p=0$. 0026), between MPO/apoAI ratio and apoAII level $(R=-$ $0.764, p=0.0023)$ and between $\mathrm{MPO} /$ apoAI ratio and HDL-C concentration $(R=-0.670, p=0.012)$ was noted.

\section{Discussion}

Coronary artery disease, including its chronic form stable coronary artery disease, is an example of the clinical condition which progress and development depend on the co-existence of the risk factors [1-4]. Oxidative modification of HDL particles by MPO may contribute to the development of progression atherosclerosis in stable coronary artery disease [5]. In our studies smokers and former smokers with SCAD were excluded, and the results of the patients were compared to non-smoking control [11]. All SCAD patients were treated with statin 
and acetyl salicylic acid according to the ESC Guidelines on the treatment of stable coronary artery disease [10]. However, in all our patients the lipid and lipoprotein levels varied from low to high, suggesting dyslipidemia and dyslipoproteinemia of the study subjects despite an unquestioned concentration of TC and LDL-C. They had significantly reduced HDL-C and apoAI but increased concentration TG, apoB (apoB-containing lipoproteins triglyceride-rich lipoproteins (TRLs)), MPO and inflammatory markers (hsCRP, TNF- $\alpha$, IL-6) level. For these reasons it was decided to divide patients into groups in which the concentration of MPO was the factor differentiating SCAD patients. The division of patients into groups according to the increasing concentration of MPO caused the selection of patients along with deteriorating inflammatory markers and worsening dyslipidemia and dyslipoproteinemia. In the group of patients with MPO concentration $<200 \mathrm{ng} / \mathrm{ml}$, decrease HDL-C and apoAI concentration was accompanied by an increase TG, apoB and inflammatory markers but MPO level was insignificant. However, $\mathrm{MPO} / \mathrm{apoAI}$ and MPO/HDL-C ratios were moderately elevated. These results suggest that dyslipidemia and dyslipoproteinemia deepening of inflammation in SCAD patients. In the group of patients with MPO200-300 ng/ml higher MPO concentration caused deterioration of apoAI concentration, increased levels of markers of inflammation and a significant increase MPO/ apoAI and MPO/HDL-C ratios. In the group of patients with concentration of $\mathrm{MPO}>300 \mathrm{ng} / \mathrm{ml}$, apoAI, inflammatory markers (MPO, hsCRP, TNF- $\alpha$, IL-6) level and $\mathrm{MPO} / \mathrm{apoAI}$ and MPO/HDL-C were significantly worsened, and were significantly higher in comparison to controls and to MPO $<200 \mathrm{ng} / \mathrm{ml}$ SCAD patients. These results suggest that increase of inflammation (MPO) deepening of dyslipidemia and dyslipoproteinemia of patients SCAD. In the group of all patients and patients with $\mathrm{MPO}<200 \mathrm{ng} / \mathrm{ml}$ and with MPO 200-300 ng/dl positive correlations was found between $\mathrm{MPO}$ and MPO/apoAI ratio and between MPO and MPO/HDL-C ratio. These positive correlations suggest that a moderately elevated inflammation can cause an increase $\mathrm{MPO} / \mathrm{apoAI}$ and $\mathrm{MPO} / \mathrm{HDL}-\mathrm{C}$ ratios [12]. Positive correlations between MPO level and hsCRP concentration as well as between MPO concentration and IL-6 level in patients with MPO > $300 \mathrm{ng} / \mathrm{ml}$ suggest that increasing levels of inflammatory markers may cause an increase in MPO concentration. However, significant negative correlations between $\mathrm{MPO} /$ apoAI ratio and apoAI, apoAII and HDL-C levels suggest that MPO concentration may significantly decrease apoAI, apoAII and HDL-C levels. These results showed that the increase of inflammation (MPO) deepening of dyslipidemia and dyslipoproteinemia of SCAD patients $[12,13]$.

The concentration of Lp PLA2 was non-statistically increased in our SCAD patients [14]. LpPLA2 is a marker of inflammation and is a link between lipid metabolism and low-grade inflammation characteristic of cardiovascular or metabolic syndrome $[15,16]$. The concentration of LpPLA2 is characterized by minimal biological variability and high specificity for vasculitis and is nondepending from insulin resistance [17]. Therefore, SCAD patients with a high MPO concentration $>300 \mathrm{ng} / \mathrm{ml}$ and a high concentration of inflammatory markers and reduced concentration of apoAI and HDL-C in which LPPLA2 was increased are at the risk of ACS and stroke [18-20]. Our studies have shown elevated levels of TG, apoB, and apoB/apoAI, TG/HDL-C ratios, and indicated an increasing concentration of triglyceride-rich lipoproteins (apoB-containing lipoproteins). TRLs caused an increase in the concentration of inflammatory markers and MPO levels in the artery wall $[8,9,19-21]$. These results suggest that a high $\mathrm{MPO}$ and TG level and disorder of apoB/apoAI and TG/HDL-C ratios together with high inflammatory markers decreased HDL-C and apoAI concentration and disturbed the composition of HDL-C and apoAI in HDL, and the anti-inflammatory and anti-oxidative functions of HDL particles [7, 13]. Khine HW et al. [5] showed that increased MPO indexed to HDL particle concentration (MPO/HDLp) is associated with increased risk of incident CVD (cardiovascular disease) events in a population initially free of CVD. MPO may contribute to atherosclerotic plaque instability [22].

Our results for the first time indicated that moderate dyslipidemia and dyslipoproteinemia caused chronic inflammation in artery wall and slowly increased the concentration of MPO, inflammatory markers and $\mathrm{MPO} / \mathrm{apoAI}, \mathrm{MPO} / \mathrm{HDL}-\mathrm{C}$ ratios and together gradually deterioration of dyslipidemia and dyslipoproteinemia. We also showed for the first time that the main problem of SCAD patients is not the high concentration of total cholesterol and LDL-C but the progressive increase chronic inflammation and the accompanying increase in TG and apoBcontaining lipoprotein concentration, gradually and slowly decline of HDL-C, apo AI and lowering the HDL particles function. The rapid increase in systemic inflammation may cause an increase in $\mathrm{MPO}$ concentration which may cause ACS and stroke in patients who had low lipid and lipoprotein at the beginning of studies [5]. In the future, prospective studies of SCAD patients are needed, in groups with moderate and advanced inflammation which markers of inflammation, lipids, apoB-containing lipoproteins and HDL particles will be determined. Understanding the relationship between inflammation of apoBcontaining lipoproteins and HDL particles will contribute to the implementation of effective, causal treatment of patients with SCAD [23, 24]. 


\section{Conclusion}

The results suggest that moderate dyslipidemia and dyslipoproteinemia deepening of inflammation and inflammation slowly induce increase MPO concentration which decrease apoAI and HDL-C level and disturb HDLs function. The increasing MPO level and MPO/HDL-C, MPO/ apoAI ratios can differentiate the SCAD of patients at the risk of acute coronary syndrome (ACAD) and stroke.

\section{Abbreviations \\ ACS: Acute coronary syndromes; HDL-C: High density lipoprotein - cholesterol; HOSCN: Hypothiocyanate; hsCRP: High sensitivity C-reactive protein; IL- 6: Interleukine-6; LDL-C: Low density lipoprotein cholesterol; LPPLA2: Lipoprotein associated phospholipase A2; MPO: Myeloperoxidase; non-HDL -C: Non high density lipoprotein cholesterol; PON 1: Paraoxonase 1; SCAD: Stable coronary artery disease; TC: Total cholesterol; TNF-a: Tumor necrosis factor-a}

\section{Acknowledgements}

Not applicable

\section{Funding}

Medical University of Lublin, Poland - DS41/2017, DS41/2018, DS1/2018.

\section{Availability of data and materials}

Please contact author for data requests.

\section{Authors' contributions}

ZB collected boot serum and selected patients of the study, DD performed the experiments. EK have planned the study, drafting the manuscript, performed and interpretation data analysis. JS coordinated of the study. All authors have read and approved the final version of the article.

\section{Ethics approval and consent to participate}

Written informed consents were obtained from all the participants. The study was approved by the Ethics Committee of the Medical University in Lublin, Poland (number KE-0254/66/2012) and conducted according to the principles outlined in the Declaration of Helsinki.

\section{Consent for publication}

Not applicable

\section{Competing interests}

The authors declare that they have no competing interests.

\section{Publisher's Note}

Springer Nature remains neutral with regard to jurisdictional claims in published maps and institutional affiliations.

\section{Author details}

'Department of Laboratory Diagnostics, Medical University, Street Chodźki 1, 20-093 Lublin, Poland. ²Department of Cardiology of the Provincial Specialistics Cardinal Stefan Wyszynski Hospital, Lublin, Poland.

Received: 7 February 2018 Accepted: 25 March 2018

Published online: 04 April 2018

\section{References}

1. Tonkin AM, Blankenberg S, Kirby A, Zeller T, Colquhann D, Funke-Kaiser A, Haque W, Hunt D, Keech AC, Nestel P, et al. Biomarkers in stable coronary heart disease, their modulation and cardiovascular risk: the LIPID biomarker study. Int J Cardiol. 2015;201:499-507.

2. Ganz P, Heidecker B, Hveem K, Jonasson C, Kato S, Segal MR, Sterling DG, Williams SA. Development and validation of a protein-based risk score for cardiovascular outcomes among patients with stable coronary heart disease. JAMA. 2016:315:2532-41.

3. Leibowitz M, Karpati T, Cohen-Stavi CJ, Feldman BS, Hoshen M, Bitterman H, Suissa S, Balier RD. Association between achieved lowdensity lipoprotein levels and major adverse cardiac events in patients with stable ischemic heart disease taking statin treatment. JAMA. Intern Med. 2016;176:1105-13.

4. Stefanescu A, Siegmund B, Ndrepepa G, Koppara T, Pavaci H, Mehilli J, et al. Prognosticvalue of plasma myeloperoxidase concentratio in patients with stable coronary artery disease. Am Heart J. 2008;155:356-60.

5. Khine HW, Teiber JF, Haley RW, Khera A, Ayers CR, Rohatgi A. Association of the serum myeloperoxidase/high-density lipoprotein particle ratio and incident cardiovascular events in a multi-ethnic population: observations from the Dallas heart study. Atherosclerosis. 2017;263:156-62.

6. Pan B, Yu B, Ren H, Willard B, Pan L, Zu Z, Shen X, Ma Y, Li X, Chenguang Niu C, Kong J, Kang S, Chen YE, Pennathur S, Zheng L. High-density lipoprotein nitration and chlorination catalyzed by myeloperoxidase impair its effect of promoting endothelial repair. Free Radic Biol Med. 2013;60:272-81.

7. Gugliucci A, Menini T. Paraoxonase-1 and HDL maturation. Clin Chim Acta. 2015:439:5-13.

8. Kacprzak M, Zielinska M. Prognostic value of myeloperoxidase concentration in patients with ST-segment elevation myocardial infarction treated with primary percutaneous coronary intervention. Int J Cardiol. 2016;223:452-7.

9. Roman RM, Camargo PV, Borges FK, Rossini AP, Polanczyk CA. Prognostic value of myeloperoxidase in coronary artery disease: comparison of unstable and stable angina patients. Coron Art Dis. 2010; 21:129-36.

10. Mancia G, Fagard R, Narkiewicz K, et al. ESH/ESC guidelines for the management of arterial hypertension: the task force for the management of arterial hypertension of the European Society of Hypertension (ESH) and of the European Society of Cardiology (ESC). J Hypertens. 2013;31:1281-357.

11. Hadfield K, Pattison DL, Brown BN, Hou L, Rye K-A, Davies MJ, Hawkins $\mathrm{CL}$. Myeloperoxidase-derived oxidants modify apolipoprotein $\mathrm{A}-\mathrm{I}$ and generate dysfunctional high-density lipoproteins: comparison of hypothiocyanous acid ( $\mathrm{HOSCN}$ ) with hypochlorous acid $(\mathrm{HOCl})$. Biochem J. 2013;449:531-42.

12. Shao B, Pennathur S, Heinecke JW. Myeloperoxidase targets apolipoprotein $\mathrm{Al}$, the major high density lipoprotein, for site-specific oxidation in human atherosclerotic lesions. J Biol Chem. 2012;287:6375-86.

13. Huang $Y$, Wu Z, Rivanto M, Gao S, Levison BS, Gu X, et al. Myeloperoxidase, paraoxonase-1, and HDL from functional ternary complex. J Clin Invest. 2013;123:3815-28.

14. Wallentin L, Held C, Armstrong PW, Cannon CP, Davies R, Grnger CB, Hagstrom F, et al. Lipoprotein-associated phospholipase A2 activity is a marker of risk but not a useful target for treatment in patients with stable coronary heart disease. J Am Heart Assoc. 2016;5:e003407.

15. Kimak A, Strycharz-Dudziak M, Bachanek T, Kimak E. Lipids and lipoproteins and inflammatory markers in patients with chronic apical periodontitis. Lipids Health Dis. 2015;14:162-9.

16. Kimak A, Kimak E, Solski J, Tymczyna B, Bachanek T. Chronic apical periodontitis as risk factor atherosclerosis and artery disease. J Lab Diagn. 2017;53(2):79-84

17. Kinney GL, Snell-Bergeon JK, Maahs DM, et al. Lipoprotein-associated phospholipase a(2) activity predicts progression of subclinical coronary atherosclerosis. Diabetes Technol Ther. 2011;13:381e7.

18. Honda H, Hirano T, Ueda M, Kojima S, Mashiba S, Hayase $Y$, Michihata T, Shishido K, Takahashi K, Hosaka N, Ikeda M, Sanada D, Shibata T. Associations among apolipoproteins, oxidized high-density lipoprotein and cardiovascular events in patients on hemodialysis. PLoS One. 2017; 12(5):e0177980

19. Kimak E, Hałabiś M, Baranowicz-Gąszczyk I. Relationship between serum lipid, lipoprotein, triglyceride-rich lipoprotein, and high-density lipoprotein particle concentrations in post-renal transplant patients. J Zhejiang-Univ Sci B. 2010;11:249-57.

20. Kimak E, Hałabiś M, Baranowicz-Gąszczyk I, Solski J, Książek A. Association between moderately oxidized low-density lipoprotein and high-density lipoprotein particle subclass distribution in hemodialyzed and post-renal transplant patients. J Zhejiang-Univ Sci B. 2011;12:365-71.

21. Kimak E, Bylina J, Solski J, Magdalena Hałabiś M, Baranowiczga szczyk 1. Książek A. Association between lipids, lipoproteins composition of HDL particles and triglyceride-rich lipoproteins, and LCAT and CETP activity in post-renal transplant patients. Cell Biochem Biophys. 2013; 67:695-702. 
22. Zhou B, Zu L, Chen Y, Zheng X, Wang Y, Pan B, Dong M, Zhou E, Zhao M, Zhang Y, Zheng L, Gao W. Myeloperoxidase-oxidized high density lipoprotein impairs atherosclerotic plaque stability by inhibiting smooth muscle cell migration. Lipids Health Dis. 2017;16:3-14.

23. Teng N, Maghzal GJ, Talib J, Rashid I, Antony K, Lau AK, Stocker R. The roles of myeloperoxidase in coronary artery disease and its potential implication in plaque rupture. Redox Rep. 2017;22:51-73.

24. Schwartz EA, Reaven PD. Lipolysis of triglyceride-rich lipoproteins, vascular inflammation, and atherosclerosis. Biochim Biophys Acta. 1821;2012:858-66.

Submit your next manuscript to BioMed Central and we will help you at every step:

- We accept pre-submission inquiries

- Our selector tool helps you to find the most relevant journal

- We provide round the clock customer support

- Convenient online submission

- Thorough peer review

- Inclusion in PubMed and all major indexing services

- Maximum visibility for your research

Submit your manuscript at www.biomedcentral.com/submit 